\section{Os movimentos sociais e a ditadura brasileira (1964-1985): considerações sobre a participação da Ordem dos Advogados do Brasil - OAB*}

\section{Social movements and the Brazilian dictatorship (1964-1985): considerations on the participation of the Lawers Association of Brazil - OAB}

\section{Resumo}

Este artigo aborda importante capítulo da história política brasileira, qual seja, o início do golpe militar de 1964 até a sua extinção em 1985. Tema de aspecto complexo e multifacetado, o foco neste texto será o estudo da atuação dos movimentos sociais durante esse período, com maior ênfase para a Ordem dos Advogados do Brasil - OAB, uma categoria profissional que foi bastante participativa, bem como os métodos, as razões e o sentido de seu modus operandi no regime militar brasileiro. $\mathrm{O}$ presente estudo tem como premissa a necessidade de analisar a questão sob duas chaves diferentes, mas interligadas: as transformações no sistema institucional dos aparelhos do Estado e a evolução do cenário político mais amplo, considerando neste estudo a agência dos movimentos sociais, inclusive seus mecanismos de resistência ao regime instaurado.

Palavras-chave: Política. Estado brasileiro. Golpe militar. Movimentos Sociais. Ordem dos Advogados do Brasil.

\begin{abstract}
This article addresses an important chapter of Brazilian political history, that is, the beginning of the military coup of 1964 to its demise in 1985. Theme complex and multifaceted aspect, the focus here will be the study of the action of social movements during this period, with greater emphasis to the Lawyers Association of Brazil (Ordem dos Advogados do Brasil - OAB), a professional category which was very participative, and the methods, the reasons and the meaning of their modus operandi in the Brazilian military regime. This study is premised on the need to examine the issue from two different keys, but interconnected: transformation in the institutional systems of the State apparatus and the evolution of the broader political scenario, considering here the agency of social movements, including their mechanisms resistance measures introduced.
\end{abstract}

Keywords: Policy. Brazilian state. Military coup. Social Movements. Ordem dos Advogados do Brasil.
Trabalho apresentado à disciplina "Processo Constituinte, Constituição e Constitucionalismo no Brasil Contemporâneo", ministrada pelos professores doutores Cícero Araujo e Antônio Sérgio Rocha.

1 Aluna especial do Programa de Pós Graduação do Departamento de Ciência Política da Universidade de São Paulo, segundo semestre letivo do ano de 2013. 


\section{Introdução}

O presente trabalho foi elaborado como requisito para a disciplina "Processo Constituinte, Constituição e Constitucionalismo no Brasil Contemporâneo" e teve como inspiração a aula denominada "A sociedade contra o Estado", que mostrou como os movimentos sociais existiram (e resistiram!) durante o período do Golpe Militar brasileiro, iniciado no ano de 1964 (precisamente no dia $1^{\circ}$. de abril, quando o então presidente da República, Jango, foi deposto e Ranieri Mazzili, o presidente da Câmara dos Deputados, assumiu a presidência) e extinto em 1985. Com base nessa aula, a necessidade de melhor compreender como os grupos sociais atuaram durante o regime militar cresceu e resultou nas pesquisas que agora são apresentadas neste trabalho.

No tocante aos movimentos sociais, alguns autores defendem que a sociedade brasileira, desde o início do golpe, participou ativamente, protestando contra a presença dos militares no poder, por meio de debates, de manifestações públicas patrocinadas pelos movimentos sociais, dentre eles: o movimento estudantil, os movimentos sindicais, as ligas camponesas etc.

Além desses grupos, merece destaque também a Ordem dos Advogados do Brasil - esse último com atuação bastante peculiar já que, inicialmente, para combater o espectro da instauração do regime comunista apoiou o golpe, mas depois defendeu com afinco a volta ao Estado de Direito e á democracia.

Importa-nos neste estudo, demonstrar como se deu essa peculiar atuação da Ordem dos Advogados do Brasil - OAB como categoria profissional organizada e, com isso, propor uma interpretação da experiência política brasileira que resultou na Assembleia Constituinte e na promulgação da Constituição Federal em 1988.

Neste trabalho, portanto, primeiro abordaremos a importância dos movimentos sociais como agentes de transformação da realidade no Brasil. Logo após, demonstraremos como a OAB mudou sua forma de se relacionar com o Estado durante o período de vigência do golpe.

Assim, no subitem "Cronologia de um relacionamento", falamos em momentos de crise, por entender que dentro de um relacionamento de simpatia, de apoio e de aliança existente entre o governo e a Ordem, começaram a surgir algumas crises e, como consequência delas, um franco processo de desgaste. to de crise, o segundo momento e os demais que levaram a ruptura desse enlace. Com efeito, depois de tantas crises, veio um previsível desgaste dessa relação cuja ruptura pode ser averiguada pelos temas debatidos e referendados na VII Conferência dos Advogados realizada na cidade de Curitiba, no ano de 1978, sob o governo de Ernesto Geisel. Para entender um pouco mais sobre essa conferência, faremos uma breve análise do documento intitulado "Anais da VII Conferência Nacional da OAB".

No item seguinte, demonstraremos que, logo após a ruptura, passado o período de distensão ocorrido no governo Geisel, durante o governo de seu sucessor, Figueiredo, a Ordem passou a agir de forma ainda mais atuante, crítica, combativa. E, juntamente com outros seguimentos da sociedade civil brasileira, lutou pelo fim do regime de exceção e pela volta do Estado de Direito, por meio de importantes ações pontuais que serão descritas no último tópico deste trabalho, a saber, "Anos 80: mobilização popular e as intervenções da OAB em prol do fim do regime militar".

Depois de nos debruçarmos sobre os referidos termos, por fim, faremos nossas considerações finais.

\section{Os movimentos sociais. 0 golpe militar. A Or- dem dos Advogados do Brasil}

\subsection{A importância dos movimentos sociais brasi- leiros e suas conquistas}

Como já apontamos em outra ocasião (MOLINA, 2011, p. 23; 90), os movimentos sociais se constituíram em elementos de grande relevância na história das conquistas sociais em nosso país. Assim, eles nascem da iniciativa popular, cujo objetivo tem origem e é motivado pelas mazelas ocorridas no interior da sociedade seja pela imposição de um regime autoritário, seja entre o universo do capital em detrimento ao trabalho, pela exclusão de certos grupos sociais, pela assimetria de gênero e de raça, dentre outros destemperos.

Com efeito, por meio desses movimentos são engendrados elementos de resistência que acabam por alterar a realidade.

Certo é que durante o período de regime militar, muitos grupos resistiram ao autoritarismo imposto, à supressão dos Direitos Fundamentais que se observava, ao excesso de violência, ao aniquilamento da liberdade, à imposição da censura...

Pode-se, assim, elencar alguns grupos sociais de 
destaque desse período, dentre os quais: os estudantes (União Nacional dos Estudantes - UNE); a Igreja Católica, que mesmo dividida entre as chaves "direita" e "esquerda", contou com inúmeros religiosos (padres, freis, bispos, cardeais) na luta contra os militares com pregações, manifestações etc.; com o movimento do custo de vida, com os movimentos feministas e das mães de mortos e desaparecidos políticos, com a Associação Brasileira de Imprensa - ABI; com os sindicatos que lutavam com greves e manifestações e também com as categorias profissionais organizadas, como é o caso da OAB.

Passaremos agora a tratar especificadamente da $\mathrm{OAB}$.

A OAB é importante entidade representativa de classe, foi criada após a revolução de 1930 e exerceu relevante papel durante o Regime Militar.

Falaremos um pouco sobre esse papel.

\subsection{Cronologia de um relacionamento: $o$ casamen- to e a separação}

a) O Golpe Militar de 1964 - o início: um desejado enlace

A postura da instituição foi inicialmente de apoio ao golpe. Com efeito, a OAB-SP (ORDEM DOS ADVOGADOS DO BRASIL [201-?a]', por exemplo, durante esse período inicial, teve sua atuação marcada pela mera "posição de natureza institucional", defendendo somente as prerrogativas dos advogados que defendiam presos políticos, como consta em sua página institucional. Deve-se elucidar que, nesse período, uma postura mais crítica acerca do novo regime não foi observada.

Pensando em termos nacionais, para o Conselho Federal da OAB (ORDEM DOS ADVOGADOS DO BRASIL $[201-? \mathrm{~b}]:^{2}$

a ação das Forças Armadas foi vista como uma medida emergencial para evitar o desmantelamento do estado democrático. Dessa forma, a Ordem recebeu com satisfação a notícia do golpe, ratificando as declarações do presidente Povina Cavalcanti, que louvaram a derrocada das forças subversivas. Povina parabenizou a atuação do Conselho, considerando-a lúcida e patriótica ao alertar, durante a reunião realizada a 20 de março, os poderes constituídos da República para a defesa da ordem jurídica e da Constituição. (grifo nosso).

2 Nesse sentido, consultar "História da OAB - O Estado de Exceção", texto institucional, sem data de publicação. Publicado no site da instituição.
Observa-se, portanto, que no âmbito nacional a Ordem dos Advogados mostrava inquestionável apoio ao novo regime que se instalava.

Ocorre que enlaces enfrentam crises. E entre o Estado (estruturado com base no Regime Militar) e a OAB não ocorreu algo diverso disso. Passaremos agora a relatá-las.

b) Problemas na lua de mel (1964-1967) - primeiro momento de crise

Transcorridos os primeiros meses do golpe, o Conselho Federal da Entidade de Classe percebeu o crescimento do autoritarismo e das arbitrariedades cometidas pelos militares, que não expressavam o desejo de abandonar o poder e de convocar novas eleições - como esperava a $\mathrm{OAB}$.

Como, aliás, esperava parcela significativa da sociedade brasileira!

O primeiro passo dado pela $\mathrm{OAB}$, para contrapor-se ao regime, segundo consta no texto "História da $\mathrm{OAB}$ - O Estado de Exceção", (ORDEM DOS ADVOGADOS DO BRASIL, [201-?b]). ocorreu em junho de 1964, quando a Ordem decidiu que os advogados com os direitos políticos suspensos pelo governo poderiam continuar a exercer a profissão.

O segundo passo foi dado na sessão extraordinária de 15 de outubro do mesmo ano. Nessa ocasião, os Conselheiros protestaram contra os atentados e perseguições praticados em prejuízo de alguns advogados. Por exemplo, os agravos sofridos pelo presidente da seccional de Goiás, Rômulo Gonçalves, por requerer o cumprimento do habeas corpus concedido ao advogado José Zacarioti, preso arbitrariamente, como bem relata texto contido na página da Ordem dos Advogados. (ORDEM DOS ADVOGADOS DO BRASIL, [201-?b]).

O regime transcorreu e com o seu recrudescimento a Ordem reage, eis o prenúncio de um novo momento de crise.

c) 1968 -1970: regime endurece e OAB reage - segundo momento de crise

Nessa época, além das questões de natureza institucional da Ordem (suspensão dos direitos civis dos advogados, dentre outros problemas), pesava sobre toda a sociedade brasileira, o rigor do AI-5.

O Ato Institucional No 5 ou AI-5 foi o quinto de uma série de decretos emitidos pelo regime militar brasileiro nos anos seguintes ao Golpe Civil-Militar de 1964 no Brasil e - sobrepondo-se à soberania da Constituição 
de 24 de janeiro de 1967 - dava poderes extraordinários ao Presidente da República, suspendendo várias garantias constitucionais, como a concessão de habeas corpus, do direito de votar e ser votado nas eleições sindicais, dentre outras. $^{3}$

Esse ato institucional foi criado sob o governo de Costa e Silva e, como relatam Araújo e Maciel (2002, p. 31-35; 65), em maio de 1969, o presidente fizera anunciar a convocação de uma comissão de juristas para elaborar uma reforma política, por meio de emenda constitucional que incluiria a extinção do AI-5, voltando a ter plena vigência a Constituição de 1967 - aquela que havia institucionalizado o regime militar e que entrou em vigor no dia da posse de Costa e Silva, a saber, 15 de março de 1967.

Assim, não mais haveria cassações de mandatos, nem recesso do Congresso e das Assembleias, intervenções nas universidades ou suspensão do habeas corpus. Com a reforma da Constituição voltaria a prevalecer o Estado de Direito - mesmo não democratizado (as eleições presidenciais continuariam indiretas), o país seria ao menos constitucionalizado.

Entretanto, uma semana antes da data prevista para assinatura da emenda, o presidente sofreu derrame cerebral e em virtude de não haver previsão constitucional para tal situação de emergência, ele foi sucedido por uma Junta Governativa Provisória, também conhecida como a Segunda Junta Militar, vindo a falecer poucos meses depois.

A emenda constitucional, contendo a extinção do AI-5, foi esquecida!

Em lugar disso, a Junta Militar outorgou a Emen-

3 Eis as garantias constitucionais suspensas pelo AI-5: O Presidente da República podia decretar a intervenção nos estados e municípios, "sem as limitações previstas na Constituição" (art. $3^{\circ}$ ). Conforme o artigo $4^{\circ}$, o Presidente da República, ouvido o Conselho de Segurança Nacional, e "sem as limitações previstas na Constituição", podia suspender os direitos políticos de quaisquer cidadãos por 10 anos e cassar mandatos eletivos federais, estaduais e municipais. Pelo artigo $5^{\circ}$, a suspensão dos direitos políticos, significava: I - cessação de privilégio de foro por prerrogativa de função; II - suspensão do direito de votar e ser votado nas eleições sindicais; III - proibição de atividades ou manifestação sobre assunto de natureza política; IV - aplicação, pelo Ministério da Justiça, independentemente de apreciação pelo Poder Judiciário, das seguintes medidas: a) liberdade vigiada; b) proibição de frequentar determinados lugares; c) domicílio determinado. $\mathrm{O}$ artigo 10 suspendia a garantia de habeas corpus, nos casos de crimes políticos, contra a segurança nacional, a ordem econômica e social e a economia popular. (BRASIL, 1968). da Constitucional $\mathrm{n}^{\circ} 1$, também chamada pelos juristas de "Constituição de 1969", que impediu a posse do vice-presidente da República, o jurista Pedro Aleixo e deu posse ao general Médici.

E sobre a permanência do AI-5, eis a informação constante no site da Ordem dos Advogados (ORDEM DOS ADVOGADOS DO BRASIL, [201-?b]):

A partir da decretação do AI-5, a OAB, que já vinha se manifestando contra o endurecimento do regime ditatorial, erigiu-se como porta-voz do restabelecimento da ordem jurídica. Embora nem sempre atendida, diversas foram as vezes em que a entidade interveio, exigindo apuração de responsabilidade e denunciando os atentados à dignidade da pessoa humana, tanto em relação a prisões políticas, de advogados ou não, quanto a atos arbitrários promovidos pela censura ou outros mecanismos de coerção instituídos. (grifos nosso).

Percebe-se que o apoio anunciado no início do golpe pela Ordem dos Advogados do Brasil já não mais existe neste momento.

No dia 30 de outubro de 1969, o general Emilio Garratzu Médici assumiu a Presidência da República, dando início ao período denominado "anos de chumbo", no qual o autoritarismo do governo foi a tônica do regime político e as ações violentas ainda mais intensas.

d) 1969-1974: Anos de Chumbo: as crises se agravam

Diante dos abusos cometidos pelo governo militar, segundo relata o texto História da OAB (ORDEM DOS ADVOGADOS DO BRASIL, [201-?b])., entre 1969 e 1970, as principais medidas adotadas pela Ordem contra o regime foram:

1) Protestos, por ofício, endereçados ao ministro da Justiça ou registrados em ata, contra a prisão de diversos advogados brasileiros, destacando-se: Sobral Pinto, George Tavares, Heleno Fragoso (vice-presidente da Seção da Guanabara), Augusto Sussekind de Moraes Rego (representante da Seção do Paraná), Albertino de Souza Oliva, Mário Edson de Barros, João Pereira da Silva, Levy Raw de Moura e Ruy César do Espírito Santo, entre outros, que trabalharam como defensores de presos políticos e mesmo de outros advogados, que no exercício da profissão foram acusados de subversão.

2) Parecer sobre a violação da Declaração dos Direitos da Pessoa Humana e sobre a inconstitucionalidade da Portaria no $11-B$ - medida essa elaborada pelo ministro da Justiça, que tornou obrigatória a censura prévia da Polícia Federal na divulgação de livros e periódicos 
no território nacional, de acordo com o Decreto-lei n. ${ }^{o}$ 1.077, de 1970 .

3) Pronunciamento contra a edição do Ato Institucional $n^{\circ} 14$, a 10 de setembro de 1969, que instituiu a pena de morte, provocando intensos protestos.

Sabe-se, ainda, que no período mais difícil da ditadura militar, a OAB-SP, presidida por Cid Vieira de Souza, teve papel significativo tanto na defesa das prerrogativas dos advogados, que eram perseguidos, quanto no apoio à população, para que os direitos fossem preservados.

E em 1972, o Presidente do Conselho Federal e os Presidentes dos Conselhos Seccionais da Ordem dos Advogados do Brasil, em sua $6^{\text {a }}$ Reunião, realizada em Curitiba, Estado do Paraná, elaboram documento denominando "Declaração de Curitiba", afirmando ser competência dos advogados a defesa da ordem jurídica e da Constituição da República.

$\mathrm{Na}$ ocasião declaram que a condição primordial para o exercício dos direitos individuais e o normal funcionamento das instituições democráticas, somente seria possível com o restabelecimento das garantias do Poder Judiciário e da plenitude do habeas corpus.

Tal documento previa, ainda, que:

[...] a repressão à criminalidade - mesmo quando exercida contra os inimigos políticos - deve fazer-se sob o império da lei com respeito à integridade física e moral dos presos e com observância das regras essenciais do direito da defesa, notadamente a comunicação da prisão à autoridade judiciária competente; o cumprimento dos prazos legais de incomunicabilidade e sem qualquer restrição ao livre exercício da atividade profissional do advogado. (ORDEM DOS ADVOGADOS DO BRASIL; [201-?c])

Consta lembrar que, utilizando métodos escusos (que calaram vozes em porões escuros e sujos!), o governo Médici exterminou os movimentos tidos como os mais radicais, a saber: subversivos e guerrilheiros - cumpre lembrar que a maior guerrilha brasileira, a Guerrilha do Araguaia, foi derrotada, abrindo espaço para que o sucessor de Médici, Ernesto Geisel, iniciasse a anunciada abertura política.

É sobre esse período que falaremos logo abaixo.

e) 1974-1979. A distensão e a improvável reaproximação

Geisel assumiu o governo prometendo retorno à democracia por meio de processo "gradual e seguro". Tal processo recebeu o nome de "distensão" e previa a adoção de um conjunto de medidas políticas liberalizantes, cuidadosamente controladas pelo Executivo Federal.

Todavia, em virtude da tensa relação observada entre a ordem e o governo, em 1976 a OAB foi representada pelo procurador-geral da República para ser obrigada a prestar contas ao Tribunal de Contas da União $\square$ o que teria enorme impacto em sua autonomia e gestão $\square$ e dada a gravidade da situação, considerou-se necessário consultar o plenário do Conselho Federal sobre como deveria agir a presidência. Por unanimidade, foi aprovada a proposta de que a $\mathrm{OAB}$ não deveria prestar contas ao TCU $\square$ esse episódio acirrou ainda mais os ânimos entre a instituição e o governo.

No cenário político nacional, o senador Petrônio Portela (Piauí) que liderou a chamada "Missão Portela" e o general Golbery do Couto e Silva, da Casa Civil, preparavam propostas para viabilizar a chamada transição, isto é, medidas que de forma "lenta, gradual e segura" (ARAUJO, 2013) ${ }^{4}$ conduzissem o País de volta ao regime democrático, ao restabelecimento pleno dos direitos civis, políticos e sociais. Todavia, o general Ernesto Geisel recuou perante o crescimento das oposições no Congresso, aprovando uma série de medidas arbitrárias.

Com relação à OAB, Rocha (2013) ensina que o ano de 1977 marcaria uma alteração na sua postura dessa entidade de classe com a eleição do jurista e historiador Raymundo Faoro (1977-1979). Com efeito, os ânimos inflamaram devido ao impacto do autoritário do "Pacote de abril", instituído pelo governo em 1977 - esse pacote determinou o recesso do Parlamento, baixou decretos-lei e emendou a Constituição, de modo a interferir no processo democrático. Exemplos disso: o fechamento temporário do Congresso Nacional, aumento do mandato dos próximos presidentes da república para seis anos, criação da figura do "senador biônico" .

Desse modo, então, a $\mathrm{OAB}$ passou a ser uma das principais instituições da sociedade civil (ao lado, principalmente, da Associação Brasileira de Imprensa - ABI e da Conferência Nacional dos Bispos do Brasil - CNBB)

4 Na expressão do Presidente Ernesto Geisel. Sobre a natureza dual do regime autoritário e a dinâmica de sua "distensão" veja o texto "O processo constituinte brasileiro, a transição e o Poder Constituinte”.(ARAUJO, 2013).

5 Senador biônico foi o nome com que ficaram conhecidos os parlamentares eleitos indiretamente por um Colégio Eleitoral, em virtude da Emenda Constitucional número 8, de 14 de abril de 1977. 
comprometidas com a volta do Estado de Direito e com o processo de abertura, fomentado pelo que se convencionou denominar "Missão Portela"6 - destaca-se, neste estudo, a atuação do senador Petrônio Portela na reivindicação pela anistia ampla, geral e irrestrita dos presos políticos que teve o apoio e a interlocução diretos do presidente Raymundo Faoro.

Em virtude de tantas questões que necessitavam de debates, encaminhamentos e decisões, a OAB Federal passou a promover conferências com abrangência nacional, entre seus pares. Com isso, algumas conferências foram realizadas ${ }^{7}$, tendo destaque a VII Conferência, realizada em Curitiba cujo teor será descrito no próximo item.

\section{Notas sobre a VII conferência da OAB Nacio-} nal ${ }^{8}:$ a declarada ruptura

6 Sobre o Senador Petrônio Portela: De março de 1971 a 1972, ocupou a presidência do Senado. Em agosto de 1973 tornou-se líder do Governo no Senado e presidente nacional da Arena até 1975. Foi reconduzido à presidência do Senado, em fevereiro de 1977, com a missão de buscar o entendimento entre o Governo e a Oposição em torno de reformas político-institucionais que substituíssem o regime de exceção pelo Estado de direito, mas, em $1^{\circ}$ de abril de 1977, o Governo decretou o recesso do Congresso, que só voltou a funcionar 14 dias mais tarde. O senador pode completar sua missão em setembro de 1978, quando o Congresso aprovou a Emenda Constitucional $\mathrm{n}^{\circ} 11$, revogando os atos institucionais, inclusive o AI-5. Em $1^{\circ}$ de fevereiro de 1979, Petrônio Portella deixou a presidência do Senado e em 15 de março, quando o General Figueiredo tomou posse na presidência da República, assumiu o Ministério da Justiça, vindo a falecer no dia 6 de janeiro de 1980, em Brasília. (BRASIL, [201-?.]).

7 As conferências ocorreram durante todo golpe militar, mas destacarmos neste estudo, aquelas realizadas no Governo Geisel e Figueiredo, ou seja, após o período inicial de apoio ao regime, pela OAB. V Conferência da OAB Nacional, realizada em 1974, no Rio de Janeiro/RJ. Presidente da Ordem José de Castro Filho. Presidente do Brasil Ernesto Geisel. VI Conferência da OAB Nacional, realizada em 1976, em Salvador/BA. Presidente da Ordem Caio Mário Pereira. Presidente do Brasil Presidente do Brasil Ernesto Geisel. VII Conferência da OAB Nacional, realizada em 1978, em Curitiba. Presidente da Ordem Raymundo Faoro. Presidente do Brasil Ernesto Geisel. VIII Conferência da OAB Nacional, realizada em 1980, em Manaus/AM. Presidente da Ordem João Baptista Figueiredo. A VIII Conferência Nacional dos Advogados realizou-se em Manaus. Presidente da Ordem Eduardo Seabra Fragundes. Presidente do Brasil João Baptista Figueiredo. Nessa última conferência, o Conselho Federal da $\mathrm{OAB}$ escolheu uma temática que refletia o momento histórico do País, que vivenciava a pós-anistia, mas ainda estava pressionado por instrumentos do regime militar, como a Lei de Segurança Nacional. (ORDEM DOS ADVOGADOS DO BRASIL,. [2014?]).

8 A Ordem dos Advogados do Brasil, instituída no plano nacional, é composta de Seções (Seccionais) instaladas em cada um dos Estados da Federação e também no Distrito Federal.
No mês de maio de 1978, realizou-se, em Curitiba, a VII Conferência Nacional da Ordem dos Advogados do Brasil, coordenada pelo presidente da seccional, Eduardo Rocha Virmond, e com o patrocínio do Conselho Federal, liderado por Raymundo Faoro.

A reunião destacou-se por ter marcado a definitiva ruptura no relacionamento amistoso entre a $\mathrm{OAB}$ e o governo do regime militar já que o tema geral dos debates foi a volta do Estado de Direito, diante da longa vigência do AI-5, que contrastava com as promessas governamentais de abertura política, mantendo o estado de exceção ainda vigente no Brasil.

Referido evento reuniu mil e quinhentos participantes (advogados e estudantes de Direito), que tiveram a oportunidade de acompanhar os debates em torno de 47 teses apresentadas para debates e, assistir palestras e conferências dos mais renomados juristas. ${ }^{9}$

Essa reunião prenunciava os novos tempos que adviriam logo em seguida, com a Emenda Constitucional n. ${ }^{\circ} 11$, de 13 de outubro de 1978 que declarou revogados os Atos Institucionais que mutilaram a Carta Política liberal de 1946; e, com tão sonhada Anistia (Lei nº 6.683, de 28/8/1979) que beneficiou presos políticos, permitiu o retorno de 150 pessoas banidas e de 2000 exiladas, que não podiam voltar ao país sob o risco de serem presas.

Como resultado desse importante encontro, tem-se importante documento que pode ser ainda hoje consultado, a saber, "Anais da VII Conferência Nacional dos Advogados".

Passaremos, a estudá-la, pois!

\subsection{Sobre as teses propostas na conferência, algu- mas considerações}

Sem maiores rodeios, o que se discutia com afinco nessa conferência, era a institucionalização ou não das chamadas "salvaguardas" (medidas de defesa do Estado, submetidas ao poder discricionário do Chefe do Executivo).

O jurista Goffredo da Silva Telles sustentou que a

Cada seccional possui um presidente, eleito pelos advogados regularmente inscritos nos quadros da Ordem.

9 Dentre eles: Caio Mário da Silva Pereira, Sérgio Bermudes, Alberto Gomes da Rocha Azevedo, Rubens Requião, Evaristo de Moraes Filho, Victor Nunes Leal, Miguel Reale Junior, Evandro Lins e Silva, Geraldo Ataliba, René Ariel Dotti, Therezinha Zerbini, Alberto Venâncio Filho, Goffredo da Silva Telles Junior, para citar apenas alguns nomes. 
defesa do Estado deveria ficar restrita ao estado de sítio, como medida excepcional, afastadas quaisquer outras medidas, não previstas na Constituição e incompatíveis com o Estado de Direito (TELLES JÚNIOR, 1978). Telles defendia a volta ao Estado de Direito.

De outro lado, havia os defensores das salvaguardas, ${ }^{10}$ segundo eles deveria ser mantido o estado de emergência quando as circunstâncias políticas indicassem risco para a estabilidade política. Para isso, pleiteavam a institucionalização da suspensão das garantias, a aplicação da censura prévia, a suspensão do habeas corpus, a prisão sem ordem judicial, o adiamento das eleições, suspensão das imunidades parlamentares etc. Eles defendiam a permanência do estado de exceção.

Com efeito, o embate entre as duas atitudes políticas foi notório, bastante acalorado e marcou a Conferência como um dos encontros mais ricos, dinâmicos e, polêmicos! Tendo sido, certamente, o tema do encontro com maior destaque na imprensa. ${ }^{11}$

Para conhecer um pouco dos bastidores desse evento, eis o relato da ativista e esposa do jurista Goffredo Telles, Maria Eugenia R. Silva Telles (2011):

Era preciso preparar cuidadosamente a sessão da Comissão encarregada da Tese defendida pelo Goffredo. Havia riscos de toda ordem. O Ministro Petrônio Portela reuniu-se várias vezes com o nosso "Batonnier" Raymundo Faoro, buscando cooptá-lo para a tese das Salvaguardas, instando para que a Tese do Goffredo fosse adiada em Plenário, mesmo se tivesse sido aprovada na Comissão.

Nosso grupo não era numeroso, mas era muito aguerrido. Em torno do Goffredo estavam José Gregori, Luiz Baptista Pereira de Almeida, Lamartine Correa de Oliveira, Miguel Reale Junior, Alexandre Thiollier Filho, Therezinha Zerbini, Álvaro Dias, jovem político do Paraná, e numerosos Colegas do Paraná, de Minas Gerais, do Rio de Janeiro e de São Paulo.

Nós nos reunimos algumas vezes no Escritório do Colega Lamartine Correa de Oliveira para preparar a sessão da Comissão e para trabalhar

10 Seu grande defensor foi Oscar Dias Correa, antigo líder da UDN, deputado constituinte em 1946 e depois Ministro do Supremo Tribunal Federal. Sua tese intitulava-se "Emergência constitucional no Estado de Direito" (Tese no ${ }^{\circ}$ 17) e defendia a ideia de que o Estado Democrático de Direito precisava incorporar normas que regulassem os estados de exceção que ocorrem na vida política, advogando a aplicação de medidas igualmente de exceção para defesa do Estado. (CORREA, 1978).

11 Como exemplo, vide o Anexo 2 deste trabalho. ao lado de Faoro na direção de neutralizar os esforços de Petrônio Portela, hábil político e argumentador competente.

O Conselho Federal se dividiu. Muitos de seus membros - alguns notáveis advogados e juristas - se deixaram seduzir pelo discurso governista e cerraram fileiras em prol da aprovação da Tese das Medidas de Emergência e do Estado de Emergência.

Pelo relato da autora, o clima era de debate intenso e de nítida tensão!

Isso porque, nas Comissões internas, ambas as teses foram aprovadas - mas, frise-se, a aprovação da tese defendida pelo Goffredo foi aclamada e formou-se um núcleo de resistência, contrário à ideia das Salvaguardas.

Nesse sentido, prossegue a autora, sua envolvente narrativa (TELLES, 2011):

Afinal, chegou o dia da Sessão Plenária. A expectativa era imensa. Cabia ao Presidente da Conferência sagrar as teses que iriam compor a "Declaração dos Advogados Brasileiros" e aquelas teses que seriam "adiadas", significando que seriam excluídas das Conclusões da Conferência.

Sabemos dos bastidores. Raymundo Faoro tomou seu tempo para decidir o que fazer. O apelo governamental para apoiar a tese das Salvaguardas era poderosíssimo. "O ótimo é inimigo do bom”, diziam alguns Conselheiros Federais, convencidos pela verve de Portela que acenava com a revogação de boa parte do entulho autoritário em troca das Medidas Excepcionais de Defesa do Estado.

Enfim, no dia 12 de maio, sexta-feira, depois do almoço, reuniu-se a Sessão Plenária no Teatro Guaíra. O Presidente relacionava as Teses e proclamava: APROVADA, ou então ADIADA. A proclamação foi a seguinte: Tese $n^{\circ} 7$ "Estado de Sitio e outras Salvaguardas" - APROVADA. Tese n ${ }^{\circ} 17$ "A Emergência Constitucional do Estado de Direito" - ADIADA.

O Plenário se levantou aos brados de "Viva, Viva, Viva o Brasil, Viva o Estado Democrático de Direito Pleno, Viva”, palmas e palmas. A emoção tomou conta dos corações ao som do Hino Nacional.

\section{$[\ldots]$}

Dez anos depois, em 5 de outubro de 1988 foi promulgada a Constituição da Republica Federativa do Brasil.

No documento Anais da Conferência contêm a íntegra das Teses, a "Declaração dos Advogados Brasileiros" e o discurso do Presidente Faoro (CONFERÊN- 


\section{CIA NACIONAL DA ORDEM DOS ADVOGADOS DO}

BRASIL, 1978), documentos de suma importância para retratar a época.

Antes de abordar os anos 1980, importante lembrar que, em 1979, a Declaração de Curitiba, aprovada na VII Conferência Nacional dos Advogados, tinha semelhanças com a declaração de mesmo nome aprovada em 1972, pois manifestava o repúdio dos advogados pelo estado de exceção ainda vigente no país. O novo documento clamava, ainda, pela revogação dos atos institucionais e pela anistia ampla, geral e irrestrita. ${ }^{12}$

Ainda no ano de 1979 (em junho), o Conselho Federal da $\mathrm{OAB}$ se pronunciaria sobre o projeto de Lei da Anistia enviado ao Congresso Nacional e em agosto de 1979, após forte pressão da sociedade civil.(BRASIL, 1979), ele foi aprovado.

Apesar dos progressos observados ao longo da década de 1970, o regime ainda subsistia e ainda muita coisa haveria de ser feita para ser anunciado o seu fim.

Chegam os anos 1980 !

\section{Anos 80: mobilização popular e as interven- ções da OAB em prol do fim do regime militar}

O início dos anos 1980 foi marcado pela mobilização popular em defesa do estado de direito, das eleições diretas dos representantes políticos e da convocação da Assembleia Constituinte. Reivindicava-se o direito do povo à participação política, por meio da eleição de um representante que respeitasse a vontade da maioria e de uma Constituição que garantisse os direitos sociais e individuais, tais como: a liberdade, a segurança e a justiça e, que substituísse a então vigente, elaborada durante o governo Castelo Branco, em 1967.

Nesse momento, a OAB encontrava-se bastante visada pelos militares e órgãos de segurança contrários à abertura política, principalmente por reivindicar a convocação de Assembleia Nacional Constituinte que defendesse o País do autoritarismo, restituindo-lhe o pleno estado democrático de direito e consolidando a verdadeira abertura, considerada insubsistente com a vigência de leis como a Lei de Segurança Nacional.

Desse modo, a Ordem dos Advogados do Brasil

12 O conteúdo deste documento pode ser lido, na íntegra, no Anexo 1, deste artigo. foi alvo de um dos muitos atentados a bomba que ocorreram no período, sendo o episódio Lyda Monteiro da Silva, o mais famoso e dramático. ${ }^{13}$

Com isso, confirma-se que juntamente com outras entidades representativas da sociedade civil, como a Associação Brasileira de Imprensa - ABI (BERTONCELLO, 2007), ${ }^{14}$ a Conferência Nacional dos Bispos do Brasil CNBB e os sindicatos (NORONHA, 2009) ${ }^{15}$, a OAB, mesmo que tardiamente, como bem destacou Rocha (2013), passou a lutar para combater a repressão política e instaurar a ordem democrática que assegurasse a defesa dos direitos humanos.

Além da participação da OAB no "Movimento Diretas-Já", que representava a transição entre o regime militar e um possível Estado de Direito que despontava, essa entidade de classe realizou outras importantes intervenções. Sobre a campanha pelas Diretas e pela Democratização, recomenda-se a leitura do texto de Bertoncello (2007).

Passaremos agora a descrever ações pontuais da $\mathrm{OAB}$ durante esse período.

\subsection{A criação do Conselho de Defesa dos Direitos da Pessoa Humana}

Neste estudo, vale destacar a gestão de Eduardo Seabra Fagundes que exigiu a apuração de denúncias dos abusos contra as garantias individuais. De fato, o presidente da Ordem teve atuação destacada por censurar a

13 No site da OAB, consta o relato do episódio Lyda Monteiro em que às $13 \mathrm{~h} 40$ do dia 27 de agosto de 1980, a funcionária Lyda Monteiro da Silva, com mais de quarenta anos de serviços prestados à $\mathrm{OAB}$, foi fatalmente vitimada por um atentado a bomba, desconhecendo-se o autor do ato terrorista. $\mathrm{O}$ atentado, executado na forma de um envelope que chegara como correspondência destinada ao presidente do Conselho Federal, Eduardo Seabra Fagundes, ocorreu quando a Seccional de São Paulo e o presidente nacional da Ordem, na qualidade de delegado do Conselho de Defesa dos Direitos da Pessoa Humana, insistiam na identificação de agentes e ex-agentes dos serviços de segurança suspeitos do atentado sofrido pelo jurista Dalmo Dallari - sequestrado e agredido em 02 de julho de 1980, em São Paulo - que terminou arquivado. (ORDEM DOS ADVOGADOS DO BRASIL, [201?c].).

14 Como aponta Edison Bertoncello, a atuação da imprensa nacional durante o período militar sofreu mudanças. No início tímida, depois agressiva. (BERTONCELLO, 2007, cap. 4-5).

15 Sobre a atuação dos sindicatos, sobre a relevância das greves e sobre a transição política, indica-se a leitura do seguinte texto: "Ciclo de greves, transição política e estabilização: Brasil, 1978-2007 (NORONHA, 2009). 
inoperância das decisões e por lutar contra o sigilo que regia as deliberações do Conselho de Defesa dos Direitos da Pessoa Humana - CDDPH. ${ }^{16}$

Para a Ordem eram endereçados inúmeros pedidos e reivindicações de pessoas atingidas pelo desrespeito aos direitos humanos. Por exemplo: a tentativa de reabertura do processo do desaparecimento do deputado Rubens Paiva, a investigação sobre as ossadas de presos políticos encontradas em Rio Verde (GO) e o acompanhamento dos trabalhos de localização da casa de Petrópolis (a "casa da morte"), utilizada como local de refúgio pelos órgãos de segurança, dentre outros.

\subsection{Atuação para a revogação da Lei de Segurança Nacional}

A OAB empenhou-se também em ver revogada a Lei de Segurança Nacional por entender que aquele instrumento de natureza totalitária era incompatível num regime que pretendia ser liberal-democrata, defendendo, portanto, que os crimes contra a segurança do Estado deveriam ser tratados pelo Código Penal para evitar novas perseguições.

Com efeito, a revisão dessa lei, em 1978, teve grande repercussão entre os advogados, que a considerava fraude. A Lei $\mathrm{n}^{\circ}$ 6.620, de 17 de dezembro de 1978, foi prorrogada duas vezes, até ser totalmente revogada, em 1983, pela nova e ainda vigente (BRASIL, 1983), Lei de Segurança Nacional, a saber, Lei 7.170 de 14 de dezembro de 1983.

\subsection{A criação da Comissão de Direitos Humanos no Conselho Federal da OAB}

No mesmo dia do atentado à funcionária da OAB Lyda Monteiro da Silva, por meio da Resolução n. ${ }^{\circ}$ 120/80, o presidente Seabra Fagundes criou a Comissão de Direitos Humanos no Conselho Federal da OAB e apresentou os 14 nomes eleitos para sua composição, a saber: Barbosa Lima Sobrinho, Dalmo de Abreu Dallari, Evandro Lins e Silva, Heráclito da Fontoura Sobral Pinto, J. Bernardo Cabral, José Cavalcanti Neves, José Danir Siqueira do Nascimento, José Paulo Sepúlveda Pertence, José Ribeiro de Castro Filho, Miguel Seabra Fagundes,

16 Órgão colegiado mais antigo de defesa dos Direitos Humanos da República, instituído pela Lei no 4.319 , de 16 de março de 1964 , alterado pela Lei $\mathrm{n}^{\circ} 5.763$, de 15 de dezembro de 1971 (SOCIEDADE, 2014).
Nilo Batista, Raul de Sousa Silveira, Raymundo Faoro e Victor Nunes Leal

Em 1982, a Comissão de Direitos Humanos da Ordem dos Advogados do Brasil - Seção do Rio de Janeiro -, compilou uma lista de 333 "mortos e desaparecidos" políticos sob o governo militar no período 1964-1981.

A comissão teve papel de destaque na denúncia da violação aos Direitos Humanos, ocorrida nesse período e ainda hoje se encontra em funcionamento. ${ }^{17}$

\subsection{A questão dos estrangeiros}

$\mathrm{A} O \mathrm{OAB}$ repudiou a agressão do governo, que empreendera mudança radical na tradicional e característica política nacional de hospitalidade aos estrangeiros; e enviou ao ministro do Supremo Tribunal Federal, telegrama endossando os termos do habeas corpus requerido pelo advogado Erasmo Villa Verde (notório defensor dos perseguidos pela ditadura) (ORDEM DOS ADVOGADOS DO BRASIL, 2014), em prol da liberdade de consciência e do direito de ser, segundo a sua convicção religiosa.

Também por meio do Conselheiro Sobral Pinto, a Ordem expressou sua repulsa à tentativa do governo de expulsar do País o presidente da União Nacional dos Estudantes - UNE, Francisco Javier Alfaya.

Em virtude desses fatos, a ordem resolveu constituir comissão que, em caráter de urgência, examinasse a situação dos estrangeiros em face da Constituição Federal e do Estatuto dos Estrangeiros, tendo em vista que este criara restrições aos alienígenas aqui residentes que mantivessem atividades político-partidárias.

O próprio Estatuto dos Estrangeiros, matéria do Projeto de Lei $\mathrm{n}^{\circ}$ 9/80, foi objeto de pesadas críticas dos setores mais expressivos da opinião pública, destacando-se a OAB, a Associação Brasileira de Imprensa - ABI e, principalmente, a Conferência Nacional dos Bispos do Brasil - CNBB, já que grande parte dos padres católicos estrangeiros estava na mira das autoridades porque incentivavam protestos populares (por exemplo, os sacerdotes franceses Aristides Camio e François Gouriou, acusados de incitar invasões de terra no sul do Pará, foram condenados e passaram 2 anos e 4 meses na prisão).

Nesse item elencamos algumas ações pontuais da $\mathrm{OAB}$ contra o regime militar que ainda subsistia!

O desfecho desse capítulo da história foi a convo-

17 Sobre a Comissão Nacional dos Direitos Humanos da OAB (ORDEM DOS ADVOGADOS DO BRASIL, [2013?]). 
cação da Assembleia Constituinte, que contou com advogados deputados, e a elaboração da nova Carta Política brasileira, em outubro de 1988.

Com base nisso, uma nova fase da história brasileira pode ser escrita!

Depois de tecer considerações sobre atuação da $\mathrm{OAB}$ durante o período militar, seguem as considerações finais.

\section{Considerações finais}

$O$ resultado da pesquisa apresentada neste artigo sinaliza a existência de setores mais críticos da OAB, de setores que não apoiavam totalmente o regime militar instaurado. Nesse sentido, ressalte-se que, no período mais difícil da ditadura militar, a OAB-SP, teve papel significativo tanto na defesa das prerrogativas dos advogados, (perseguidos e torturados), quanto no apoio à população, para que os direitos de toda a Nação fossem preservados.

Por outro lado, também não se pode esquecer que no início do regime militar, a entidade de classe dos advogados foi - sob o pretexto de manutenção da ordem favorável ao golpe militar e à instalação do regime anunciado por seus representantes.

Como momento crucial da atuação mais crítica (menos governista, portanto) da OAB, vale destacar os debates ocorridos na VII Conferência Nacional da Ordem, cujo tema era "O Estado de Direito" preparou o ambiente ideal para a discussão sobre a restauração da democracia em nosso país, por meio de teses apresentadas por renomados juristas.

E essa mudança na forma como a OAB passou a se relacionar com o regime é, acredita-se, o resultado das mudanças nas práticas coletivas de camadas sociais que se tornaram mais autônomas, criticas e combativas frente ao controle estatal. E, de outro lado, o enfraquecimento do controle do núcleo político dirigente.

De fato, no início da década de 1980, calem que a grande ânsia por abertura e o crescimento das forças de oposição emergentes em diversas localidades nacionais geravam as mais contraditórias emoções, de desconsolo e de esperança, de ativismo e de medo. Nesse cenário, a $\mathrm{OAB}$, por meio de seus membros, sem dúvida, emergia como força fomentadora de mudanças sociais.

Sobre esse complexo e ainda não decodificado capítulo da história brasileira ficam ainda algumas questões carentes de respostas: onde estão os grupos sociais ou pessoas que foram sufocados pela violência dos militares e desapareceram no curso da história? Qual o papel da sociedade para que não surjam mais regimes tão autoritários e violentos? Como fica o imaginário das pessoas e famílias que sofreram com a violência? Qual foi realmente o papel da $\mathrm{OAB}$ ao longo do regime militar? Devemos considerar essa participação tardia/inoperante ou pontual/certeira?

Muitas são as indagações, mas certo é que busca da cidadania pela sociedade civil - incluindo-se as ações pontuais da $\mathrm{OAB}$ - tem direta relação com os direitos adquiridos e ainda vigentes, inseridos no texto constitucional, no capítulo dos Direitos Fundamentais.

Diante de tais considerações, dúvida não resta sobre a importância das reivindicações feitas pelas vozes dos movimentos sociais, vozes sufocadas, mas resistentes que existiram no interior do regime militar.

\section{Referências}

ARAUJO, Caetano Ernesto Pereira de; MACIEL, Eliane Cruxên Barros de Almeida. A comissão de alto nível: história da Emenda Constitucional n.1, de 1969. Brasília: Senado Federal, 2001. Disponível em: <http://www2.senado.leg.br/bdsf/bitstream/handle/id/154/AComissaodeAltoNivel.pdf?sequence=3 >. Acesso em: 09 fev. 2016 .

ARAUJO, Cícero. O processo constituinte brasileiro, a transição e o Poder Constituinte. Lua Nova, São Paulo, n. 88, p. 327-380, 2013. Disponível em: <http:// www.scielo.br/scielo.php?script $=$ sci_arttext $\&$ pi $\mathrm{d}=$ S0102-64452013000100011 >. Acesso em: 09 fev. 2016.

BERTONCELLO, Edison. A campanha das diretas-já e a democratização. São Paulo: Humanitas, 2007.

BRASIL. Ato Institucional no 5, de 13 de dezembro de 1968. Disponível em: <http://www.planalto.gov.br/ccivil_03/ AIT/ait-05-68.htm>. Acesso em: 09 fev. 2016.

BRASIL. Decreto $n^{\circ}$ 84.143, de 31 de outubro de 1979. Regulamenta a Lei $\mathrm{n}^{\circ} 6.683$, de 28 de agosto de 1979, que concede anistia e dá outras providências. Disponível em: <http://www.planalto.gov.br/ccivil_03/decreto/1970-1979/D84143.htm>. Acesso em: 09 fev. 2016.

BRASIL. Lei $n^{\circ} 7.170$, de 14 de dezembro de 1983. Define os crimes contra a segurança nacional, a ordem política e social, estabelece seu processo e julgamento e dá outras providências. Disponível em: <http://www.planalto.gov. br/ccivil_03/leis/17170.htm>. Acesso em: 09 fev. 2016.

BRASIL. Senado Federal. Grandes Momentos do Parlamento Brasileiro. [201-?.]. Disponível em: <http://www. senado.gov.br/senado/grandesMomentos/portela.shtm $>$. Acesso em: 09 fev. 2016. 
CONFERÊNCIA NACIONAL DA ORDEM DOS ADVOGADOS DO BRASIL, 7., 1978, Curitiba. O Estado de Direito: Anais. Brasília: Ordem dos Advogados do Brasil, 1978.

CORREA, Oscar Dias. Emergência constitucional no estado de direito. In: CONFERÊNCIA NACIONAL DA ORDEM DOS ADVOGADOS DO BRASIL, 7., 1978, Curitiba. O Estado de Direito: Anais. Brasília: Ordem dos Advogados do Brasil, 1978. p. 407-430.

MOLINA, Sandra Cordeiro. Políticas de promoção da igualdade racial no Brasil: das estruturas aos instrumentos jurídicos. 2001. 206 f.; Dissertação (Mestrado em Direito Político e Econômico) - Coordenadoria de Pós-graduação, Universidade Presbiteriana Mackenzie, São Paulo, 2011.

ORDEM DOS ADVOGADOS DO BRASIL. A OAB - SP e o governo militar. São Paulo: OAB, [201-?a]. Disponível em: <http://www.oabsp.org.br/portaldamemoria/historia-da-oab/a-oab-sp-e-o-governo-militar/>. Acesso em: 09 fev. 2016.

ORDEM DOS ADVOGADOS DO BRASIL. Declaração de Curitiba: 1972. Brasília: OAB, [201-?c]. Disponível em: <http://www.oab.org.br/historiaoab/links_internos/ def_estado_declcuritiba.htm>. Acesso em: 09 fev. 2016.

ORDEM DOS ADVOGADOS DO BRASIL. Histórico das Conferências. Brasília: OAB, [2014?]. Disponível em: $<$ http://conferencia.oab.org.br/historico.asp $>$. Acesso em: 06 jan. 2014.

ORDEM DOS ADVOGADOS DO BRASIL. Institucional / Comissões. Brasília: OAB, [2013?]. Disponível em: $<$ http://www.oab.org.br/institucionalconselhofederal/comissoes >. Acesso em: 09 fev. 2016.
ORDEM DOS ADVOGADOS DO BRASIL. O estado de exceção. Brasília: OAB, [201-?b]. Disponível em: <http:// www.oab.org.br/historiaoab/estado_excecao.htm>. Acesso em: 09 fev. 2016.

ORDEM DOS ADVOGADOS DO BRASIL. OAB homenageia advogados que defenderam os perseguidos pela ditadura. Brasília: OAB, 31 mar. 2014. Disponível em: $<$ http://www.oab.org.br/noticia/26857/oab-homenageia-advogados-que-defenderam-os-perseguidos-pela-ditadura>. Acesso em: 09 fev. 2016.

ROCHA, Antônio Sérgio. Genealogia da Constituinte. Do autoritarismo a democratização. Lua Nova, São Paulo, n. 88, p. 29-87, 2013. Disponível em: <http://www.scielo. br/scielo.php?pid=S0102-64452013000100004\&script $=$ sci_arttext>. Acesso em: 09 fev. 2016.

SOCIEDADE civil será protagonista no Conselho Nacional dos Direitos Humanos, afirma ministra. 2014. Disponível em: <http://www.sdh.gov.br/noticias/2014/ setembro/sociedade-civil-sera-protagonista-no-conselho-nacional-dos-direitos-humanos-afirma-ministra> . Acesso em: 09 fev. 2016.

TELLES JÚNIOR, Goffredo. O estado de sítio e as outras salvaguardas. In: CONFERÊNCIA NACIONAL DA ORDEM DOS ADVOGADOS DO BRASIL, 7., 1978, Curitiba. O Estado de Direito: Anais. Brasília: Ordem dos Advogados do Brasil, 1978. p. 237-248.

TELLES, Maria Eugenia R. Silva. Em 1978, conferência da OAB marcou luta pela restauração da democracia. Migalhas, 23 nov. 2011. Disponível em: <http://www.migalhas. com.br/Quentes/17,MI145520,71043-Em+1978+conferencia $+\mathrm{da}+\mathrm{OAB}+$ marcou+luta+pela+restauracao $+\mathrm{da}+-$ democracia >. Acesso em: 09 fev. 2016. 


\section{Anexo 1}

\section{ATA DA REUNIÃO - DECLARAÇÃO DE CURITIBA VII CONFERÊNCIA NACIONAL ATA DA REUNIÃO - DECLA- RAÇÃO DE CURITIBA - VII CONFERÊNCIA NACIONAL}

Os advogados brasileiros, presentes e representados na VII Conferência Nacional da Ordem dos Advogados, ao reiterarem sua unidade e coesão, trazem sua palavra ao povo, ao qual pertencem e devem conta de suas preocupações e de sua conduta pública. Armados da palavra e da razão, sentem-se credenciados, ainda uma vez dentro da sombra autoritária que envolve o país, a expressar mensagem de esperança e de liberdade, clamando pelo estado de direito democrático. O Estado democrático constitui a única ordem que pode proporcionar as condições indispensáveis à existência do verdadeiro estado de direito, no qual liberdade-autonomia cede lugar à liberdade-participação que pressupõe princípios pertinentes ao núcleo das decisões políticas e a sua legitimidade institucional. Para isso não basta o voto consentido, pois só ele não constitui a essência da democracia, ao contrário: é a própria democracia que dá conteúdo de participação ao direito de voto. Expressão de ato político e democrático, e vontade que este representa, exige processo normativo integrado, desde a organização pluripartidária - representativa das várias correntes de opinião pública - às garantias da livre manifestação do pensamento, incluindo o direito de crítica ás instituições. As restrições à liberdade somente se tornam legítimas na medida em que visem à preservação do interesse coletivo - respeitado o limite infranqueável da dignidade da pessoa. $\mathrm{O}$ controle judicial, por tribunais dotados das garantias da Magistratura, cuidará de remediar qualquer lesão ou ameaça de lesão à liberdade, síntese dos direitos humanos. Os direitos fundamentais não podem sofrer agravo de grupos ou entidades privadas, e, com maior razão, não devem sofrer agravo ao abrigo das agressões que decorram das autoridades constituídas, cujo dever, primeiro será o de amparar o livre desenvolvimento daqueles direitos. Se o contrário fosse admissível, reconhecer-se- ia o absurdo da subversão da ordem pelos seus próprios agentes. Essas agressões à dignidade das pessoas não se justificam; ainda quando se dissimulam debaixo do pretexto de segurança nacional. No estado de direito, a segurança nacional constitui meio de garantir as liberdades públicas. Protege-se o Estado, para que este possa garantir os direitos individuais. A legitimidade da incriminação de atentados à segurança nacional repousa no princípio de que só pelos meios jurídicos podem ser alteradas as instituições estabelecidas pelo povo, por meio de representantes livremente escolhidos. Para que a segurança nacional se enquadre no estado de direito, garantindo a inviolabilidade dos direitos do homem, o crime pode ser defendido mediante a tipicidade de fatos externos, ofensivos a bens ou interesses jurídicos. O ilícito penal não compreende, a título de ilícito político, restrições a ideias dissidentes do regime, nem no mero exercício de meios para formá-la. Não haverá o estado de direito nem segurança nacional democraticamente entendidos, sem a plenitude do habeas corpus que assegure a primeira das liberdades e base de todas as outras a liberdade física - em regime que consagre a inviolabilidade e a independência dos juízes. O habeas corpus, cuja substância está na inteireza, consagra cinco séculos de nossa herança luso-brasileira, herança jurídica, política e moral, que devemos resguardar e transmitir a outras gerações. No estado de direito, as garantias institucionais decorrem da partilha das funções do Estado entre vários Poderes, de modo que um não amesquinhe nem anule os outros, mas se limitem mutuamente, em sistemas de fiscalização e controle recíprocos. A vigência do AI-5 faz reinar no Brasil uma situação de excepcionalidade, a mais longa da História brasileira, tradicionalmente ferida de temporários colapsos da liberdade. Declaramos, todavia, que a simples revogação do AI-5 não restauraria, por si só, o estado de direito, diante da realidade que a vigente Constituição não forma estrutura política democrática. Não se negará, dentro do estado de direito, a legitimidade de instrumentos que o defendam, ao tempo e na justa medida que defendam a liberdade dos cidadãos. No caso de grave perturbação da ordem e na eventualidade de guerra externa, dispõe a tradição do Direito brasileiro no instituto do estado de sítio, sem que na sua regulamentação se insinue o arbítrio e a irresponsabilidade. A nação se resguarda pela ação conjunta dos três Poderes e não pela usurpação de um às atribuições dos outros, em velada suspeita da incapacidade destes. Essa a instância máxima das restrições que possam ser impostas ao exercício dos poderes e aos direitos fundamentais. Se o Governo deve contar com meios prontos e eficazes para debelar situações excepcionais, serão os estritamente necessários e suficientes, respondendo pelos abusos ou excessos que cometer, quer pela via política, administrativa ou judicial. No estado de direito, a defesa das instituições não legitimaria exclusões, ostensivas ou dissimuladas, da efetiva participação política e social do povo. Cumpre, para suprimir obstáculos arbitrariamente criados, rever a legislação trabalhista do país, de nítida inspiração autoritária, ao ponto de alguns de seus dispositivos violarem a Declaração Universal dos Direitos do Homem. Sem liberdade sindical, não pode existir verdadeiro 
e autêntico direito coletivo de trabalho, que encontra nos Sindicados seus sujeitos de direito e seus agentes dinâmicos. Sem liberdade sindical não há democracia possível, não há estado de direito. Só o estado de direito reconhece os conflitos, legitima-os e os supera. Os direitos políticos, longe de obstarem os direitos sociais, constituem a única via pacífica para a sua obtenção e o seu exercício. Direitos sociais e direitos políticos são o conteúdo do estado de direito, que, por ser Estado ético, repele a ideia da injustiça, situada nas desigualdades decorrentes da excessiva riqueza de uns, da extrema miséria da maioria. Uma política fiscal justa e eficiente há de atenuar isenta de arbítrio, com a criação de tributos, seu aumento e discriminação por atos que atendam ao consentimento popular e às normas constitucionais. Para sua honra, os advogados debatem e estudam a realidade nacional, com a inteligência, o equilíbrio e o senso de responsabilidade que historicamente lhes reconhecem os brasileiros. Identificam no autoritarismo o principal desvio ao livre desenvolvimento da vida jurídica, política e social do país. Situam na liberdade de participação a maior preocupação dos seus estudos, participação cuja amplitude exige a participação nacional, que lance o esquecimento sobre os ódios do passado. A anistia, embora não leve, por si só, ao estado de direito, clamor de consciência jurídica do país, não é reivindicação exclusiva de classes ou grupos, mas constitui o necessário pacto de convivência dos brasileiros. As promessas governamentais, para que atendam aos reclamos da opinião pública, devem converter-se em ação, com brevidade, em favor da paz e da concórdia dos brasileiros.

Curitiba, 12 de maio de 1978. Anais da VII Conferência Nacional da OAB Curitiba, 1978.

\section{Anexo 2}

Figura 1- "Estado democrático, já"
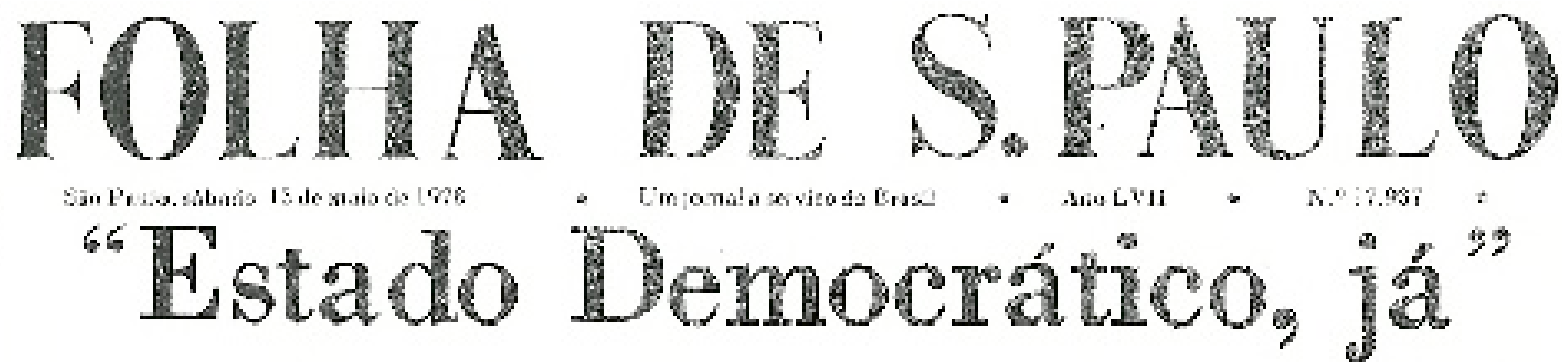

Conferencia da $0 \mathrm{AB}$ encerra-se com a "Deciaraçāo dos Advogados Brasileiros"

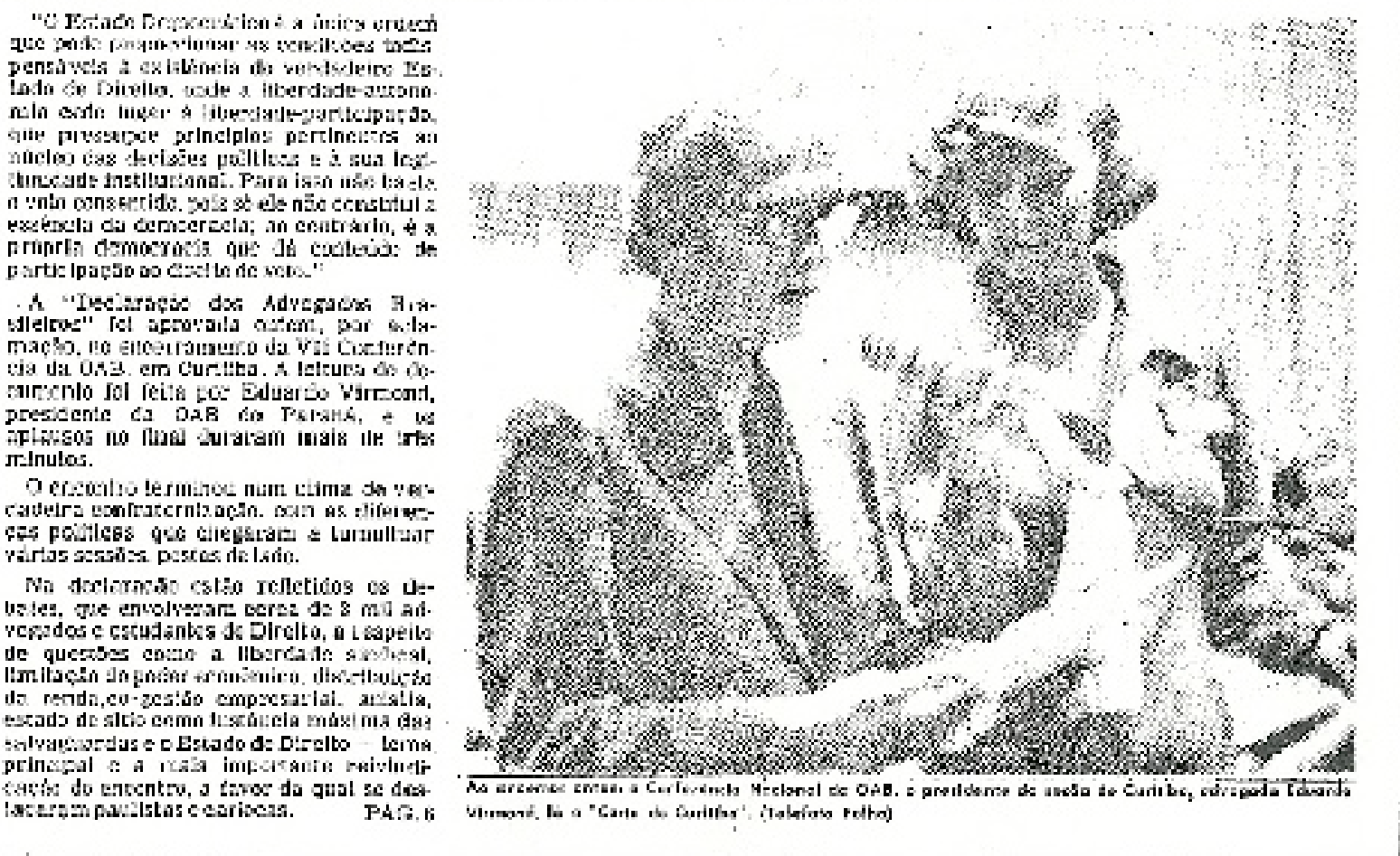


Figura 2 - “OAB refuta tese de salvaguardas”

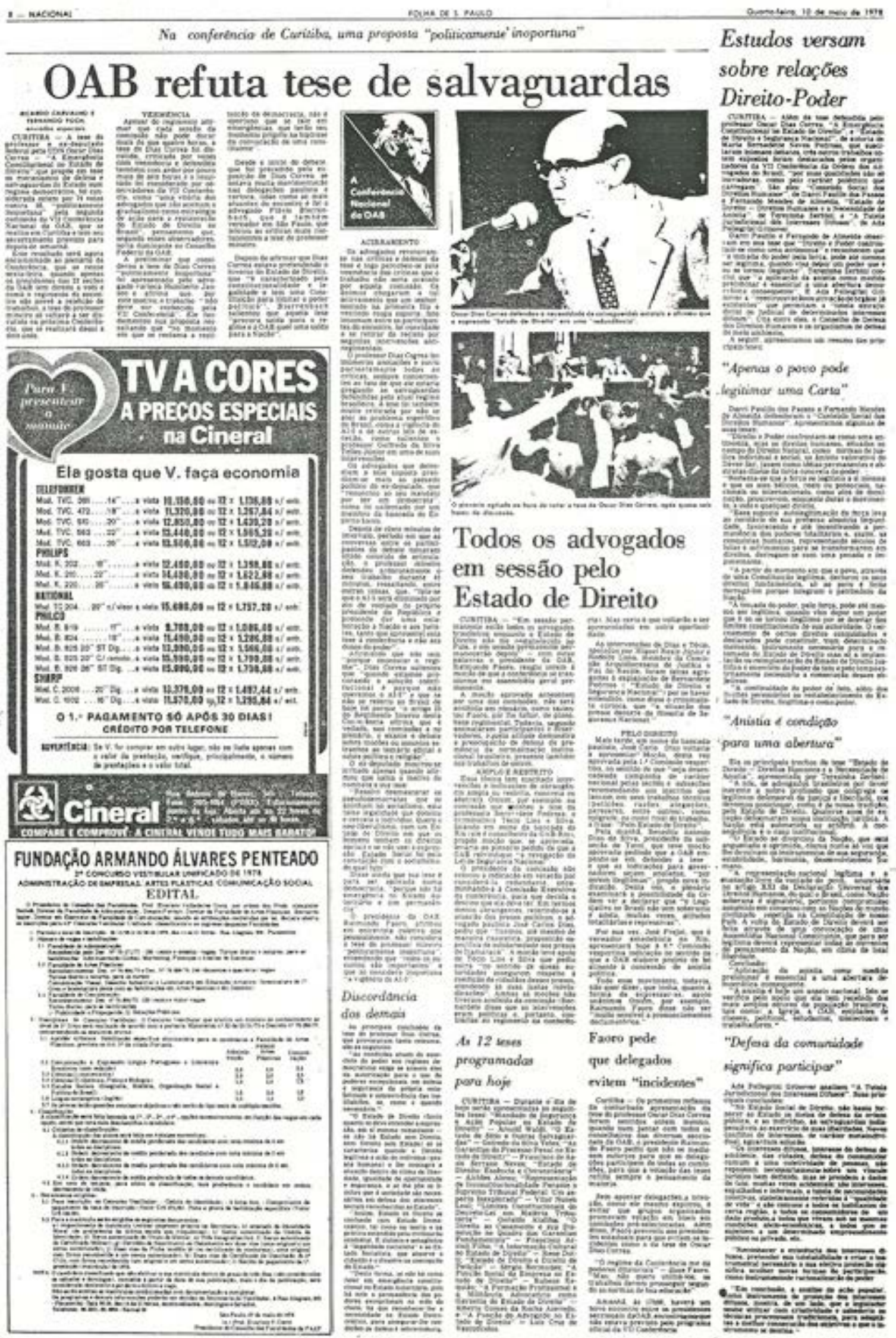

